\title{
Smokers' unprompted comments on cigarette additives during conversations about the genetic basis for nicotine addiction: a focus group study
}

\author{
Sydney E. Philpott, Sarah Gehlert and Erika A. Waters
}

\begin{abstract}
Background: Research designed to elicit smokers' cognitive and affective reactions to information about chemicals that tobacco companies add to cigarettes ("additives") found that knowledge is limited. However, little is known about smokers' unprompted thoughts and feelings about additives. Such information could be used to shape future communication efforts. We explored the content and possible functions of spontaneous statements about cigarette additives made by smokers during a study examining reactions to learning about the genetic link to nicotine addiction.
\end{abstract}

Methods: Adult smokers $(N=84)$ were recruited from a medium-sized Midwestern city. Focus groups $(N=13)$ were conducted between April-September 2012. Data were analyzed by 2 coders using thematic analysis.

Results: Comments about cigarette additives arose without prompting by the focus group moderator. Three main themes were identified: (1) discussing additives helped participants navigate the conceptual link between smoking and genetics, (2) additives were discussed as an alternative mechanism for addiction to cigarettes, and (3) additives provided an alternative mechanism by which cigarette smoking exacerbates physical harm. Notably, discussion of additives contained a pervasive tone of mistrust illustrated by words like "they" and "them," by statements of uncertainty such as "you don't know what they're putting into cigarettes," and by negative affective verbalizations such as "nasty" and "disgusting".

Conclusions: Participants had distinct beliefs about cigarette additives, each of which seemed to serve a purpose. Although mistrust may complicate communication about the health risks of tobacco use, health communication experts could use smokers' existing beliefs and feelings to better design more effective anti-smoking messages.

\section{Background}

Dozens of toxic chemicals are either added to cigarettes or produced during tobacco combustion [1]. Many of these compounds are carcinogenic [2-6], and some chemicals are added to increase product appeal, ease smoking initiation, discourage cessation, or promote relapse [7].

There are 93 known potentially harmful chemicals in cigarettes [8]. "Constituents" are by-products of the tobacco growing and manufacturing process or result from the combustion processes. "Additives" refer to non-tobacco

\footnotetext{
* Correspondence: waterse@wustl.edu

Division of Public Health Sciences, Washington University in St. Louis School of Medicine, St. Louis, Missouri, USA
}

substances that a manufacturer introduces into the tobacco, paper, or filter [9]. Many studies have examined knowledge, perceptions, and beliefs about cigarette additives and constituents. In general, laypeople are aware that tobacco companies add chemicals to cigarettes or tobacco [10]. While people tend not to know the quantity of chemicals added to cigarettes [11] they are suspicious of additives [12-15]. However, they are less aware of tobacco constituents $[14,16,17]$, in some cases erroneously believing that "natural" cigarettes are safe [18-21].

Current literature on perceptions of cigarette additives uses a reactive approach, in which participants are asked to respond to questionnaire items $[11,15]$ or to indicate their familiarity with specific chemicals [14, 16, 22, 23]. 
However, it may be useful to assess participants' spontaneous, unprompted thoughts about additives. Spontaneous thoughts may reflect smokers' existing beliefs and ways of thinking (or "mental models") about additives and their role in the harms associated with tobacco use. These mental models, in turn, could shape how smokers interpret tobacco-related information [24-26].

Spontaneous thoughts may also provide unanticipated insights into smokers' beliefs about the health effects of smoking. For example, spontaneous comments may yield information into how smokers' thoughts and beliefs about additives relate to their smoking behaviors. Alternatively, they may provide insight into how smokers think about the biological processes, like genetics, that link smoking to specific health consequences. Understanding how smokers think about these biological mechanisms that can shape behavior may lead to more effective anti-smoking messages [27]. Finally, spontaneous utterances may be less vulnerable to social desirability than beliefs assessed via self-reported questionnaire.

Our objective was to explore links among smokers' spontaneous comments about cigarette additives, their beliefs about the identity and characteristics of such additives, and their potential health consequences. We examine only "additives" because participants never mentioned constituents.

\section{Methods}

All study materials and procedures were approved by the Washington University IRB.

We conducted a secondary analysis of focus group data collected in April-September 2012 to examine smokers' beliefs about the relationship between genetics and nicotine addiction. Full details are reported elsewhere $[25,28]$.

\section{Study sample}

Eligible participants were $\geq 18$ years old, were current cigarette smokers, self-identified as African American or White, did not consider themselves genetic experts, had attended to the news at least once in the past week, demonstrated rudimentary knowledge of the terms "gene" or "genetic," and spoke and read English [25, 28]. Participants were recruited from the community through flyers, word of mouth, and a volunteer research participant registry.

\section{Participant characteristics}

Focus groups were stratified by race and education, resulting in the following strata: higher education/African American (HA, $n=4)$, lower education/African American (LA, $\mathrm{n}=4)$, higher education/White (HW, $n=2)$, and lower education/White (LW, $n=3$ ) [25, 28]. Focus group size averaged six participants with a range of three to ten.
Of 84 participants, 41 (49\%) were women, $57(68 \%)$ had less than a Bachelor's degree, and $52(62 \%)$ identified as African American. Average age was $42.8(\mathrm{SD}=12.9)$ and 95.9\% smoked daily.

Focus groups were stratified to reflect research about racial differences in concerns about genetic research [29] and the differential prevalence of tobacco use by education $[25,28,30]$.

\section{Procedure}

Participants first provided informed consent and verified demographic and tobacco history information. Focus groups began with introductions and questions about reasons for smoking and the meaning of "genes" and "genetics." These terms were then briefly explained in lay language to establish minimal common understanding $[25,28]$. Participants shared their thoughts about possible links between genes, addiction, disease, and smoking, and then viewed a one-minute Associated Press news video (http://youtu.be/sO3X8xBr8YQ) describing the discovery of a genetic variant associated with severe nicotine addiction and increased likelihood of lung cancer [31].

Focus groups were facilitated by a race-matched moderator and note-taker. Moderators followed a semistructured interview guide that incorporated broad open-ended questions crafted to be sufficiently flexible to elicit beliefs related to the a priori constructs of interest while allowing novel themes to emerge. Moderators probed for constructs of interest using a prepared script when these constructs failed to emerge organically. All questions and probes were phrased in non-academic language. The full interview guide has been published elsewhere [28].

\section{Data analysis}

Audiorecordings were transcribed by a professional transcriber and checked for accuracy by a research assistant. The original data analysis process occurred from October 2012 to December 2013 using NVivo software [28, 32]. Discussions of additives were coded as "Additives" during the initial coding process but were not coded indepth at the time because they were not of interest for primary analyses [25, 28]. Instead, these discussions were examined in the present data analysis for reasons described previously.

This targeted analysis (October 2015 to March 2016) used thematic analysis. SP listened to all audiorecordings and read all transcripts. SP and EW used an inductive and iterative process to develop, modify, and finalize an additive-specific codebook. After the codebook was finalized, SP coded the transcripts and EW verified that the quotes adequately represented the codes and that no possible codes were overlooked [33]. SP and EW met 
regularly throughout the coding process to identify and discuss major themes, to develop preliminary models describing the findings, and to refine the models based on re-examination of the codes, themes, and their interrelationships. EW provided feedback during all stages of the data analysis and interpretation process.

\section{Results}

\section{Overview}

Comments about cigarette additives arose without probing in 10 of 13 groups (3/4 HA, 3/4 LA, 1/2 HW, $3 / 3$ LW). Specific examples included chemicals (e.g., "rat poison," "ammonia," "fiberglass," and "formaldehyde, like the embalming fluid") and biological contaminants (e.g., such as "rat turds" and "cow urine").

In addition to specific examples, three broad themes emerged: (1) navigating the conceptual link between smoking and genetics, (2) providing an alternative mechanism of addiction, and (3) providing an alternative mechanism by which cigarette smoking exacerbates physical harm. The themes, described in detail below, did not seem to differ in content by education or race. Additive comments occurred at different times in each focus group.

Nearly all additives discussions were characterized by a pervasive and persistent tone of mistrust. Mistrust was expressed in several ways, including direct expressions such as "you can't trust people these days," expressions of uncertainty such as "you don't know what they're putting into the cigarettes," and through the use of words heavily laden with negative affect such as "nasty" and "disgusting." The speakers' tones of voice, which manifested frustration, outrage, and indignation, also conveyed mistrust.

\section{Themes}

\section{Navigating conceptual link}

In five groups (2 HA, $1 \mathrm{LA}, 1 \mathrm{HW}, 1 \mathrm{LW}$ ), additive discussions seemed to serve as a mechanism for navigating and understanding the conceptual link between smoking and genetics. Quotations related to this theme also demonstrate the tone of mistrust that was interwoven throughout the spontaneous discussions of additives.

One discussion began before the video was shown, in response to the moderator asking participants about their understanding of genetic risk and its relation to smoking:

[HA-Group2] Man 3: "Well, I feel like the tobacco companies, we don't know what they put in cigarettes, you know, you really don't. So they could put something in there to make a risk to the genetics."
After watching the news story, that participant and another group member continued to process the novel genetic information by directly linking genetic risk to additives inserted into cigarettes by tobacco companies:

[HA-Group2] Man 3: "That's what I was saying earlier about the tobacco companies... If there is a problem with the genetics and...the cigarettes created it...the tobacco companies caused [it]."

Woman 2: "Because you don't know what they've could have put in it."

Man 3: "Right."

Other participants contextualized the smoking-genetic link through additives in the environment and other consumer products. The following exchange occurred in response to a moderator's question about whether participants believed the video's report describing the genetic link to smoking.

[HA-Group1] Woman 1: "[E]verything is coming up with genetics, now. And it's too much coming up... Even your food and things. So it just makes you wonder sometimes."

Moderator: "So could that apply to smoking?"

Man 1 responds: "Yes! If it has to do with...the DNA or the biology of things, if you mix something in with something that's there, then it alters it."

These comments illustrate that participants did not consider a genetic risk related to cigarette smoking to be part of a smoker's biology. They instead considered it to be a mutation spurred by the substances that tobacco companies, who participants mistrusted greatly, add to cigarettes. According to this view, in the absence of additives, there would be no genetic link to nicotine addiction.

\section{Additives cause addiction}

Participants in four groups (1 HA, 2 LA, 0 HW, 1 LW) blamed additives for addiction. These discussions were also steeped in mistrust:

[LW-Group2] Woman 1: "You never know what they're puttin' in [cigarettes] now...you don't know what it is actually causing the addiction."

[HA-Group1] Man 1: "Even with cigarettes...tobacco companies are putting everything into the tobacco...to make it more addictive." 
One group extended this idea, asserting that tobacco companies add substances for the express purpose of preventing people from quitting:

[LA-Group4] Woman 6: "I think they got something in there to make people keep - to keep their addiction..."

Woman 3: "There's something in that cigarette, I can tell you."

Woman 6: "It's something in that cigarette."

Not all participants who attributed addiction to additives mentioned nicotine by name. It is unclear whether they were unaware of the link between nicotine and addiction, or simply did not feel the need to name it, but the use of general terms such as "everything" and "something" in the quotations above suggests a lack of awareness. Nevertheless, a participant in one group used his beliefs about the addictive nature of additives to reject the news video's assertion of a genetic link to nicotine addiction:

[LA-Group2] Man 2: “... [I]f you're gonna serve tobacco then you serve tobacco. Do not extract [and reintroduce altered levels of] nicotine, do not put [in]...all them extra products...[T] he products they put in cigarettes, I believe, is the addiction. Not just the tobacco itself, which means that it's not genetic...

I think if they took all the products that they put in the cigarettes out, there would not be as many smokers as there is now."

\section{Additives exacerbate physical harm}

Participants in seven groups (2 HA, 2 LA, 1 HW, 2 LW) partially attributed specific negative health consequences of smoking to additives, rather than to tobacco itself. The tone of mistrust was less pronounced here than in other themes:

[LW-Group1] Man 6: "Well, with all the chemicals that they put in cigarettes nowadays it is - smoking is dangerous [emphasis in original]."

[HW-Group2] Man 1: "I think there probably are additives to cigarettes that make it worse you know."

Some participants followed the idea that additives (rather than tobacco) are harmful with a proposal that "natural" or additive-free cigarettes would be less harmful and therefore have less negative impact on health:
[HW-Group2] Woman 2: "I wonder how harmful additives are as compared to the tobacco itself...I wonder if...that might motivate people to - I don't know - grow their own instead. Because if you are going to [smoke], I mean maybe there are ways that we could make it healthier or not as harmful."

[LA-Group2] Woman 1: "I don't think it's the tobacco that's killin' me, it's the - it's the chemicals and stuff they put to it."

These quotes demonstrate that most additive comments were grounded in the idea that additives and tobacco manufacturers - rather than tobacco itself - are the main culprits of intensifying the harms associated with cigarettes.

\section{Discussion}

Participants spontaneously mentioned additives and other unknown substances in the context of discussing the smoking-genetic link. Additive comments appeared to serve various functions, including navigating the genetic link to smoking and blaming additives for the harms of tobacco use. Identifying specific well-known additives such as formaldehyde illustrated why additives were harmful and why tobacco companies should not be trusted.

Participants navigated the conceptual smoking-genetic link by citing additives as the perpetrator of genetic changes and contextualizing this link through additives in the environment and other consumer products. They imagined that smoking has a genetic component but felt that it is the substances added by tobacco companies that results in the genetic risk - not an inherent genetic element. Some participants argued that the presence of additives actually disproves the connection between genetics and smoking. For them, additives are the addictive substance and their existence in cigarettes demonstrates that addiction cannot be genetic.

These comments may suggest that some participants minimize the influence of genes on smoking behavior by asserting that external sources (e.g. tobacco companies) put additives in cigarettes and those additives lead to severe nicotine dependence, not the genes themselves. Participants used these statements to explain their behavior and, perhaps, deflect some responsibility for their addiction onto tobacco companies.

Using additives to justify dismissing the smokinggenetic link is consistent with other research demonstrating smokers' skepticism about the validity of research establishing a smoking-genetic link [25, 28]. For some participants, accepting that their inherited DNA (an internal characteristic out of their control) may contribute to their behavior means diminished personal 
autonomy [25, 28, 34]. However, if genetic mutations are caused by additives (an external element out of their control) rather than inherited, they retain autonomy and validate their assertions that quitting only requires sufficient willpower (an internal characteristic within their control) [25]. This is consistent with research suggesting that people simultaneously seek to reduce feelings of personal blame and maintain a sense of control over their lives [35]. However, not all participants felt this way. Future research is needed to determine the extent to which smokers believe this connection.

The tendency for participants to blame additives for the harms of tobacco use and the assertion that "natural" cigarettes might be less harmful is consistent with research examining perceptions of "light" and "low tar" cigarettes [19] and a "no additives" campaign [36]. In our study, blaming additives for addiction might have helped participants to self-justify continued smoking despite acute awareness of the health consequences. However, there was insufficient data to determine if participants entirely attributed their continued smoking to additives, so additional research is needed.

Overall, participants were generally aware of the presence of additives in cigarettes and were able to name a few specific examples, but acknowledged many unknown substances are added to cigarettes. This awareness was steeped in mistrust of tobacco companies, as manifested through participants' shared sense of uncertainty, regular use of accusatory language, indignant tones, and negative affective reactions towards additives. This is consistent with other research examining the public's understanding and opinions of cigarette additives [11, 14, 16, 22], although those studies elicited participant reactions after providing information about additives.

Participants in our focus groups also used their knowledge and beliefs about additives to interpret new health information. This may lead to the use of ineffective harm reduction strategies (e.g., smoking "natural" cigarettes) and skepticism about novel public health campaigns that discuss the harms of tobacco use. Future studies should explore these reactions to better understand smokers' opinions and behaviors. Such studies could inform communication strategies for intervention programs aimed at smoking cessation, which have shown great promise [37].

\section{Strengths, limitations, and future research}

These results represent the first research gathered on smokers' thoughts and beliefs about additives within the larger context of a study on genetics. Other studies examining beliefs about additives have purposefully elicited smokers' reactions to information provided by the study team, whereas our results are drawn from spontaneous utterances in the context of a seeminglyunrelated study. This distinction can help further scientific understanding about how smokers think about the harms of smoking and their smoking behaviors. Additionally, smoking cessation campaigns could be designed to discuss additives and their actual role in smoking behavior and ability to quit. Furthermore, the navigating the link theme suggests that smoking counter-marketing efforts could highlight how additives might alter a person's genetics or epigenome.

One strength of our study is that most participants (61\%) were African American and people with less formal education (68\%). This makes the results applicable to two demographic groups that disproportionately face difficulty quitting and have higher morbidity and mortality from smoking-related illnesses, especially cancer [38, 39].

This study should be interpreted in light of potential limitations. Results came from a secondary analysis of data for a study unrelated to smokers' beliefs about additives. Although 10/13 groups mentioned additives, the same themes did not arise in all 10 groups. In groups where additive discussions occurred, no one provided contradictory views about these themes. However, lack of probes into these viewpoints limits our ability to draw definitive conclusions about participants' beliefs about additives and their relationship to the themes we report. Lastly, while participants only referred to "additives" it is unclear if they knew the difference between constituents and additives and if this knowledge would have impacted beliefs.

Future studies could target these beliefs within other contexts, which could inform design of marketing and health communication campaigns. Although it is not possible to draw definitive conclusions about additives beliefs from this study alone, it does demonstrate that smokers' thoughts about additives arise in a variety of conversational contexts, and it highlights avenues for future research. A future campaign might explicitly refute the idea that "no-additive" cigarettes are healthy, or that it is additives-not tobacco-that are addictive. Other campaigns might identify and highlight lesser-known additives or raise the salience of additives that elicit disgust. Additionally, these findings clearly highlight the need for public education around nicotine and addiction as well as about the constituents of cigarettes.

\section{Conclusions}

Smokers in this study had distinct understandings about cigarette additives, which helped them deflect the health risks of smoking and understand the smoking-genetic link. Although mistrust may complicate communication about health risks of tobacco use, health communication experts could use smokers' beliefs and feelings to design better anti-smoking messaging. 


\section{Abbreviations}

HA: Higher education/African American; HW: Higher education/White; LA: Lower education/African American; LW: Lower education/White

\section{Acknowledgements}

Data from this manuscript was presented at the 2016 Society for Medical Decision Making in Vancouver, B.C. Canada.

\section{Funding}

This research was supported by a Mentored Research Scholar Grant awarded to E. Waters by the American Cancer Society, MRSG-11-214-01-CBBP.

\section{Availability of data and materials}

The datasets used and/or analyzed during the current study are available from the corresponding author on reasonable request.

\section{Authors' contributions}

SP contributed to the analysis and interpretation of data, manuscript synthesis, drafting, and revision. SG provided guidance on study methodology and data interpretation, and contributed to manuscript writing and revision. EW contributed to project conceptions and design, obtained project funding, analysis and interpretation of data, drafting and revision of manuscript, and provided expertise at all levels of project design, analysis, and translation. All authors have read and approved the manuscript.

\section{Ethics approval and consent to participate}

Consent to participate, all study materials and procedures were approved by the Washington University IRB. Written consent was obtained for all participants.

\section{Competing interests}

The authors declare that they have no competing interests.

\section{Publisher's Note}

Springer Nature remains neutral with regard to jurisdictional claims in published maps and institutional affiliations.

Received: 22 November 2017 Accepted: 3 April 2018

Published online: 13 April 2018

\section{References}

1. Rustemeier K, Stabbert R, Haussmann H-J, Roemer E, Carmines E. Evaluation of the potential effects of ingredients added to cigarettes. Part 2: chemical composition of mainstream smoke. Food Chem Toxicol. 2002:40(1):93-104.

2. Radford EP, Hunt VR. Polonium-210: a volatile radioelement in cigarettes. Science. 1964:143(3603):247-9.

3. Hartwig A. "Cadmium and cancer." Cadmium: From Toxicity to Essentiality. Dordrecht: Springer; 2013. p. 491-507.

4. Gibb HJ, Lees PS, Pinsky PF, Rooney BC. Lung cancer among workers in chromium chemical production. Am J Ind Med. 2000;38(2):115-26.

5. Steenland K, Boffetta P. Lead and cancer in humans: where are we now? Am J Ind Med. 2000;38(3):295-9.

6. Langård S. Nickel-related cancer in welders. Sci Total Environ. 1994;148(2-3): 303-9.

7. Alpert HR, Agaku IT, Connolly GN. A study of pyrazines in cigarettes and how additives might be used to enhance tobacco addiction. Tob Control. 2016:25(4):444-50

8. US Food and Drug Administration. Harmful and potentially harmful constituents in tobacco products and tobacco smoke; established list. Fed Regist. 2012;77(64):20034-7.

9. Geiss O, Kotzias D. Tobacco, cigarettes and cigarette smoke an overview: Institute for Health and Consumer Protection. Luxembourg: European Commission; 2007.

10. Brewer NT, Morgan JC, Baig SA, et al. Public understanding of cigarette smoke constituents: three US surveys. Tob Control. 2016;26:592-9. tobaccocontrol-2015-052897.

11. Hall MG, Ribisl KM, Brewer NT. Smokers' and nonsmokers' beliefs about harmful tobacco constituents: implications for FDA communication efforts. Nicotine Tob Res. 2013;16:343-50. ntt158

12. Morgan JC, Byron MJ, Baig SA, Stepanov I, Brewer NT. How people think about the chemicals in cigarette smoke: a systematic review. J Behav Med. 2017:1-12.
13. Pepper JK, Byron MJ, Ribisl KM, Brewer NT. How hearing about harmful chemicals affects smokers' interest in dual use of cigarettes and e-cigarettes. Prev Med. 2017:96:144-8.

14. Moracco KE, Morgan JC, Mendel J, et al. "My first thought was croutons": perceptions of cigarettes and cigarette smoke constituents among adult smokers and nonsmokers. Nicotine Tob Res. 2016;18(7):1566-74.

15. Etter J-F. Informing smokers on additives in cigarettes: a randomized trial. Patient Educ Couns. 2007;66(2):188-91.

16. Wiseman KD, Cornacchione J, Wagoner KG, et al. Adolescents' and young adults' knowledge and beliefs about constituents in novel tobacco products. Nicotine Tob Res. 2016;18:1581-7. ntw009

17. Siahpush M, McNeill A, Hammond D, Fong G. Socioeconomic and country variations in knowledge of health risks of tobacco smoking and toxic constituents of smoke: results from the 2002 international tobacco control (ITC) four country survey. Tob Control. 2006:15(suppl 3):iii65-70.

18. Byron MJ, Baig SA, Moracco KE, Brewer NT. Adolescents' and adults' perceptions of 'natural','organic'and 'additive-free'cigarettes, and the required disclaimers. Tob Control. 2016;25:517-20. tobaccocontrol-2015052560

19. Elton-Marshall T, Fong GT, Zanna MP, et al. Beliefs about the relative harm of "light" and "low tar" cigarettes: findings from the international tobacco control (ITC) China survey. Tob Control. 2010;19(Suppl 2):i54-62.

20. Cummings KM, Hyland A, Giovino GA, Hastrup JL, Bauer JE, Bansal MA. Are smokers adequately informed about the health risks of smoking and medicinal nicotine? Nicotine Tob Res. 2004;6(Suppl_3):S333-40.

21. O'Connor RJ, Lewis MJ, Adkison SE, Bansal-Travers M, Cummings KM. Perceptions of "natural" and "additive-free" cigarettes and intentions to purchase. Health Educ Behav. 2017;44(2):222-6.

22. Wakefield M, Miller C, Woodward S. Community perceptions about the tobacco industry and tobacco control funding. Aust N Z J Public Health. 1999;23(3):240-4.

23. Malone RE, Yerger V, Pearson C. Cigar risk perceptions in focus groups of urban African American youth. J Subst Abus. 2001;13(4):549-61.

24. Morgan MG. Risk communication a mental models approach. Cambridge: Cambridge University Press; 2002.

25. Waters EA, Ball L, Gehlert S. "I don't believe it." acceptance and skepticism of genetic health information among African-American and white smokers. Soc Sci Med. 2017;184:153-60.

26. Leventhal H, Brissette I, Leventhal EA. The common-sense model of selfregulation of health and illness, The self-regulation of health and illness behaviour, vol. 1; 2003. p. 42-65.

27. Cameron LD, Marteau TM, Brown PM, Klein WM, Sherman KA. Communication strategies for enhancing understanding of the behavioral implications of genetic and biomarker tests for disease risk: the role of coherence. J Behav Med. 2012;35(3):286-98

28. Waters EA, Ball L, Carter K, Gehlert S. Smokers' beliefs about the tobacco control potential of "a gene for smoking": a focus group study. BMC Public Health. 2014;14(1):1.

29. Condit CM, Parrott RL, Bates BR, Bevan J, Achter PJ. Exploration of the impact of messages about genes and race on lay attitudes. Clin Genet. 2004;66(5):402-8.

30. US Department of Health and Human Services. The health consequences of smoking - 50 years of progress: a report of the surgeon general. Atlanta: US Department of Health and Human Services, Centers for Disease Control and Prevention, National Center for Chronic Disease Prevention and Health Promotion, Office on Smoking and Health; 2014. p. 17.

31. Amos Cl, Wu X, Broderick P, et al. Genome-wide association scan of tag SNPs identifies a susceptibility locus for lung cancer at 15q25.1. Nat Genet 2008;40(5):616-22

32. Charmaz K. Constructing grounded theory: a practical guide through qualitative analysis. Thousand Oaks: Sage; 2006.

33. Bernard HR, Wutich A, Ryan GW. Analyzing qualitative data: systematic approaches. Los Angeles, CA: SAGE publications; 2016.

34. Dar-Nimrod I, Zuckerman M, Duberstein PR. The effects of learning about one's own genetic susceptibility to alcoholism: a randomized experiment. Genet Med. 2012:15(2):132-8.

35. French D, Maissi E, Marteau TM. The purpose of attributing cause: beliefs about the causes of myocardial infarction. Soc Sci Med. 2005; 60(7):1411-21.

36. Arnett JJ. Winston's "no additives" campaign: "straight up"? "no bull"? Public Health Rep. 1999;114(6):522. 
37. Zucker D, Hopkins RS, Sly DF, Urich J, Kershaw JM, Solari S. Florida's "truth" campaign: a counter-marketing, anti-tobacco media campaign. J Public Health Manag Pract. 2000;6(3):1-6.

38. DeSantis CE, Siegel RL, Sauer AG, et al. Cancer statistics for African Americans, 2016: progress and opportunities in reducing racial disparities. CA Cancer J Clin. 2016;66(4):290-308.

39. General US. The health consequences of smoking: 50 years of progress. A report of the surgeon general. Atlanta: US Department of Health and Human Services. Centers for Disease Control and Prevention. Coordinating Center for Health Promotion, National Center for Chronic Disease

Prevention and Health Promotion, Office on Smoking and Health; 2014.

Ready to submit your research? Choose BMC and benefit from:

- fast, convenient online submission

- thorough peer review by experienced researchers in your field

- rapid publication on acceptance

- support for research data, including large and complex data types

- gold Open Access which fosters wider collaboration and increased citations

- maximum visibility for your research: over $100 \mathrm{M}$ website views per year 